\title{
Expression of the Cystic Fibrosis Gene in Adult Human Lung
}

John F. Engelhardt, * Monica Zepeda, * Jonathan A. Cohn, ${ }^{\star}$ James R. Yankaskas, ${ }^{5}$ and James M. Wilson *

${ }^{*}$ Department of Molecular and Cellular Engineering, University of Pennsylvania, Philadelphia, Pennsylvania 19104-4268; ${ }^{\ddagger}$ Department of Medicine, Duke University and Veterans Administration Medical Center, Durham, North Carolina 27710; and ${ }^{\S}$ Division of Pulmonary Diseases, The University of North Carolina, Chapel Hill, North Carolina 27599-7020

\begin{abstract}
Critical to an understanding of the pulmonary disease in cystic fibrosis (CF) and the development of effective gene therapies is a definition of the distribution and regulation of CF gene expression in adult human lung. Previous studies have detected the product of the CF gene, the CF transmembrane conductance regulator (CFTR), in submucosal glands of human bronchi. In this report, we have characterized the distribution of CFTR RNA and protein in the distal airway and alveoli of human lungs. Samples from eight human lungs were analyzed for CFTR expression by in situ hybridization and immunocytochemistry. CFTR was detected in a subpopulation of epithelial cells at every level of the distal lung, including proximal, terminal, and respiratory bronchioles, and the alveoli. However, there was substantial variation in the level of CFTR expression between samples. In bronchioles, CFTR protein localized to the apical plasma membrane and was found primarily in a subpopulation of nonciliated cells. CFTR was expressed in the same distribution as the Clara cell marker $\mathrm{CC10}$ in proximal bronchioles, however, expression was discordant in the more distal bronchioles and alveoli where $\mathrm{CC10}$ was not detected. These studies suggest that epithelial cells of the distal lung may play a primary role in the pathogenesis of CF as well as expand the spectrum of target cells that should be considered in the development of gene therapies. (J. Clin. Invest. 1994. 93:737-749.) Key words: CFTR $・$ mRNA $~ \cdot$ localization $\cdot$ Clara $・$ airway
\end{abstract}

\section{Introduction}

Cystic fibrosis $(\mathrm{CF})^{1}$ is the number one genetic cause of death in the Caucasian population (1). Although multiple organs are affected in this disease, the most morbid and life threatening pathology occurs in the lung. Poor mucociliary clearance with excessive mucous production causes obstructive lung disease and chronic bacterial infections leading to bronchiectasis and respiratory failure. Isolation of the gene responsible for $\mathrm{CF}$ has provided insight into the molecular basis of this disease (2). The product of this gene, called the CF transmembrane conductance regulator (CFTR), is a chloride channel that is primarily localized to the apical surface of epithelial cells. Mecha-

Address correspondence to Dr. James M. Wilson, The University of Pennyslvania, The Institute for Human Gene Therapy, Wistar Institute, Room 204, 36th and Spruce Streets, Philadelphia, PA 191044268.

Received for publication 3 February 1993 and in revised form 31 August 1993.

1. Abbreviations used in this paper: $\mathrm{CF}$, cystic fibrosis; CFTR, cystic fibrosis transmembrane conductance regulator; COPD, chronic obstructive pulmonary disease.

The Journal of Clinical Investigation, Inc.

Volume 93, February 1994, 737-749 nisms by which mutations in this gene lead to primary defects in mucociliary clearance remain obscure.

Critical to an understanding of the basic molecular pathology of CF pulmonary disease is a definition of the normal distribution and regulation of CFTR expression in lung. Studies of CFTR expression in proximal airway structures such as human bronchus and nasal tissue have shown low levels of CFTR mRNA and protein in cells of the surface epithelium (3-5). In contrast, high levels of CFTR were demonstrated in epithelial cells of human submucosal glands that are normally restricted to the very proximal airway that is supported with cartilage (6). While these studies provide insight into pathophysiology of $\mathrm{CF}$ in the proximal airway, their relationship to disease in the bronchioles and alveoli is unclear. A previous report using in situ hybridization of human fetal lungs suggests that CFTR mRNA levels are extremely high prenatally and decline dramatically after birth (7).

The distal lung can be divided into the conducting airways, which are comprised of an extensive network of bronchioles, and alveoli, where gas exchange with the blood occurs (8). Four general structures can be identified based on morphological criteria: $(a)$ proximal bronchioles, which have a pseudostratified epithelium but in contrast to bronchi do not contain cartilage; $(b)$ terminal bronchioles, which have a simple columnar to cuboidal epithelium; $(c)$ respiratory bronchioles, which have a discontinuous simple cuboidal epithelium interrupted by alveoli and alveolar ducts; and $(d)$ alveoli, the gas-exchanging region of the lungs (8). Proximal bronchioles provide a transition from cartilaginous bronchi and contain decreasing percentages of basal cells and secretory cells as the lumen reduce in size. Smaller bronchioles normally contain only ciliated cells and nonciliated secretory cells (Clara cells), which decrease in height and appear cuboidal in most distal bronchioles. The respiratory bronchioles, which provide the transition between conducting airways and gas-exchanging alveoli, are interrupted by alveoli and alveolar ducts and contain predominantly cuboidal Clara cells with decreasing numbers of ciliated cells. The alveolar epithelium is composed of alveolar type I and II cells.

We report the localization of CFTR mRNA and protein in distal airways and alveolar regions of human lung. In an attempt to identify the cell types that express CFTR in the distal airway, we have compared the pattern of mRNA expression with the Clara cell marker CC10. These studies have implications to the pathophysiology of CF lung disease as well as the design of rational gene therapies.

\section{Methods}

Lung samples. Tissue specimens were obtained from the lungs of eight patients under a variety of circumstances. Table I summarizes salient features of the donors from which the tissues were derived. Two samples were obtained at the time of surgical lobectomy for lung cancer; 
nontumorous resected regions were selected for analysis, however, each patient had evidence of chronic obstructive pulmonary disease (COPD). These tissues were placed on ice immediately after resection and frozen in OCT within $30 \mathrm{~min}$. The remaining samples were obtained in the setting of lung transplantation. Two samples (Normall and Normal2) were obtained from portions of donor lungs that were not used for transplantation. These specimens were perfused with Uro Collins solution and stored for $0.5-4 \mathrm{~h}$ on ice. The Normall sample was excised from a resected lung after perfusion in the transplant recipient. Both were frozen in OCT within $30 \mathrm{~min}$ of resection. The remaining four samples, COPD1, COPD2, IB, and PAP, were derived from the diseased lungs of the transplant recipients who were diagnosed with COPD, idiopathic bronchiectasis, and pulmonary alveolar proteinosis, respectively. These samples were also frozen in OCT within $30 \mathrm{~min}$ of resection. All samples were stored at $134^{\circ} \mathrm{C}$ until they were sectioned.

In situ analysis of CFTR and CC10 $\mathrm{mRNA}$. Frozen sections $(6 \mu \mathrm{m})$ were fixed in PBS containing 4\% paraformaldehyde for 3-4 h followed by dehydration through a graded series of ethanol. In situ hybridization was performed as described previously (6). Briefly, dehydrated fixed sections were treated in $10 \mu \mathrm{g} / \mathrm{ml}$ proteinase- $\mathrm{K}$ at $30^{\circ} \mathrm{C}$ for $30 \mathrm{~min}$ followed by acetylation in acetic anhydride and dehydration through a graded series of ethanol. Sections were hybridized to UTP and CTP ${ }^{35} \mathrm{~S}$-labeled sense and antisense RNA probes generated from the CFTR R-domain ( $1,899-2,623 \mathrm{bp}$ [9]) and CC10 (1-361 bp [10]) cDNAs at a concentration of $10^{7} \mathrm{cpm} / \mathrm{ml}$ for $16-18 \mathrm{~h}$ at $54^{\circ} \mathrm{C}$. After washing and RNAse treatment, sections were coated in NTB-2 photoemulsion and developed at indicated times. An additional control for nonspecific hybridization included pretreatment of sections with $200 \mu \mathrm{g} / \mathrm{ml}$ RNAse A before hybridization with antisense probes.

Immunofluorescent detection of CFTR and $\mathrm{Na}^{+} / \mathrm{K}^{+}$-ATPase. CFTR protein was localized as previously described using a polyclonal antibody generated against a $\mathrm{COOH}$-terminal peptide of CFTR (residues 1468-1480) designated $\alpha-1468(6) . \mathrm{Na}^{+} / \mathrm{K}^{+}$-ATPase was localized using a mouse monoclonal antibody to the purified alpha subunit of $\mathrm{Na}^{+} / \mathrm{K}^{+}$-ATPase (11). Briefly, frozen sections $(6 \mu \mathrm{m})$ were fixed in $-20^{\circ} \mathrm{C}$ methanol for $10 \mathrm{~min}$ followed by air drying. Sections were blocked with PBS containing 20\% donkey serum (DS) and protease inhibitors $(2.5 \mu \mathrm{g} / \mathrm{ml}$ of soybean trypsin inhibitor and $1 \mu \mathrm{g} / \mathrm{ml}$ each of leupeptin, chymostatin, pepstatin, and aprotinin) for $30 \mathrm{~min}$ at room temperature. Sections were then incubated sequentially in $5 \mu \mathrm{g} / \mathrm{ml}$ $\alpha-1468$ CFTR antibody and protease inhibitors for $90 \mathrm{~min}$ followed by incubation in undiluted hybridoma supernatant against $\mathrm{Na}^{+} / \mathrm{K}^{+}$-ATPase for $60 \mathrm{~min}$. After washing in $1.5 \% \mathrm{DS} / \mathrm{PBS}$, sections were incubated in $5 \mu \mathrm{g} / \mathrm{ml}$ of both donkey anti-rabbit FITC-conjugated antibody and donkey anti-mouse Texas red-conjugated antibody for $30 \mathrm{~min}$.

Peptide competition experiments were performed by preincubating $0.5 \mathrm{mg} / \mathrm{ml}$ peptide (residues $1468-1480$ of CFTR protein) with 0.25 $\mathrm{mg} / \mathrm{ml}$ of $\alpha-1468$ in PBS containing 1.5\% DS and protease inhibitors overnight at $4^{\circ} \mathrm{C}$ before immunofluorescent staining. Control uncompeted antibody was incubated under the same conditions but without peptide. Bronchioles were analyzed for peptide-competed signal in serial sections. Additional sections were incubated with and without secondary antibody to control for nonspecific secondary antibody binding and autofluorescence, respectively.

Quantification of CFTR mRNA expression. Morphometry of CFTR in situ data involved analysis of at least four sections from each of the human lung samples analyzed. Identification of airway epithelial structures were based on the following criteria: proximal bronchiole, noncartilaginous airway with a pseudostratified epithelium; terminal bronchiole, airway with a simple columnar/cuboidal epithelium that is not interrupted by alveolar ducts; respiratory bronchiole, small diameter airway with a simple cuboidal epithelium that is interrupted by alveolar ducts; and alveoli-composed of cuboidal type II and squamous type I cells. At least six random fields of each structure (proximal bronchiole, terminal bronchiole, respiratory bronchiole, and alveoli) were analyzed for the frequency of cells expressing CFTR mRNA $>10$-fold above background levels of CFTR mRNA. Sections were analyzed for total number of CFTR mRNA-expressing cells per total number of nuclei in each structure and total number of CFTR mRNA expressing cells per square micron of total cellular area in each structure. CFTR mRNA-expressing cells were selected as those cells that expressed $>10$-fold abundance of grains as compared with acellular regions in the same field. Cellular volumes and total numbers of cells were calculated from outlined epithelial regions of proximal bronchioles, terminal bronchioles, respiratory bronchioles, and alveoli. Four of the eight samples analyzed were quantitated. Because of the high levels of mRNA expressed in a subset of cells, darkfield photomicrographs tended to be misleading in quantification due to bleeding of the saturated signal. Hence, only bright field photomicrographs were used for quantification. Results are presented as the average $\pm 1 \mathrm{SD}$. Statistical comparison was performed by the Student's $t$ test.

Due to the limiting quantities of CFTR antibody, only one section from each sample was analyzed. This gave insufficient numbers of sections and independent bronchioles to analyze for quantification. The same criteria as used with in situ hybridization were used for the identification of proximal and terminal bronchioles. Extensive autofluorescence in the most distal regions of the lung made it impossible to accurately address CFTR expression in the respiratory bronchioles and alveolar regions.

\section{Results}

CFTR mRNA localization. The cellular distribution of CFTR mRNA in lung was analyzed by in situ hybridization using an RNA probe to the $\mathrm{R}$ domain of human CFTR. Fig. 1 contains representative examples from two patients of in situ hybridization to proximal bronchioles $(A-C)$, terminal bronchioles $(D-$ $G)$, respiratory bronchioles $(H-J)$, and alveolar regions $(K-$ $M)$. Each sample demonstrated hybridization to the antisense probe that was not present when the sample was pretreated with RNAse (data not shown) or when it was hybridized to a sense probe (Fig. 1, $A, D, H$, and $K$ ). In general, hybridization was restricted to a subset of epithelial cells found in both airway and alveoli. Table II summarizes the quantification of the frequency of highly positive cells ( $>10$-fold above background; see Fig. $1 G$ for example) found at each level of the airway from four of the eight patients. Morphometric analyses were used to quantitate the frequency of highly expressing cells normalized to either cell number (number of positive cells/number of total nuclei) and cell volume (number of positive cells $/ \mu \mathrm{m}^{2}$ cell volume) within each of the epithelial structures analyzed. Although the frequency of highly positive cells normalized to total cell numbers remained similar among the eight samples

Table I. Lung Samples

\begin{tabular}{lllll}
\hline \multicolumn{1}{c}{ Donor } & Age & Sex & Disease & \multicolumn{1}{c}{ Source } \\
\hline & $y r$ & & & \\
Normal1 & 47 & F & Normal & Transplant \\
Normal2 & 42 & M & Normal & Transplant \\
COPD1 & 50 & F & COPD* & Transplant \\
COPD2 & 57 & F & COPD & Transplant \\
COPD3 & 65 & M & COPD & Lobectomy \\
COPD4 & 70 & F & COPD & Lobectomy \\
IB & 23 & F & IB $^{\ddagger}$ & Transplant \\
PAP & 41 & F & PAP & Transplant \\
& & & & \\
\hline
\end{tabular}

* Chronic obstructive pulmonary disease. ${ }^{\ddagger}$ Idiopathic bronchiectasis. ${ }^{\S}$ Pulmonary alveolar proteinosis. 

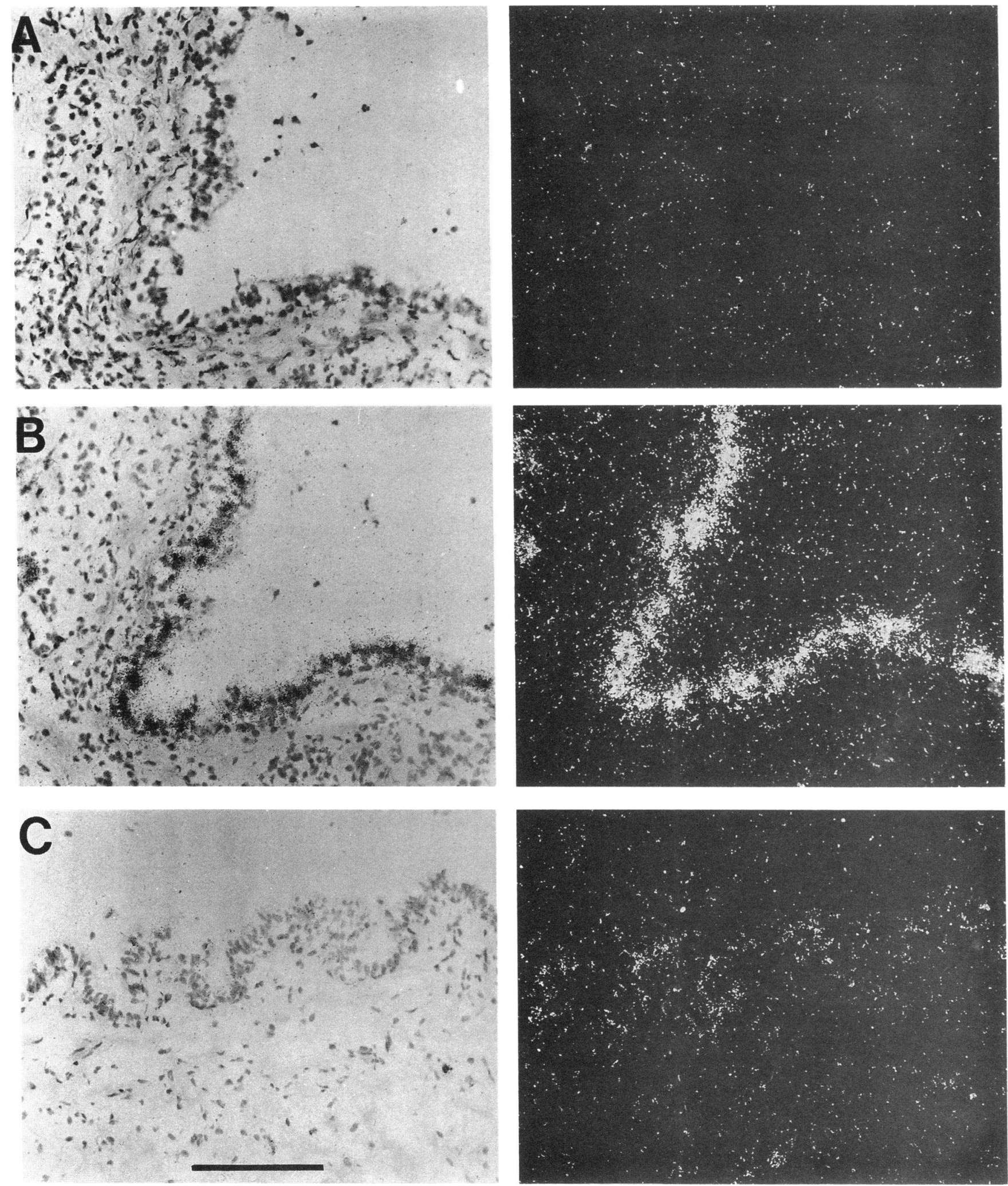

Figure 1. Localization of CFTR mRNA in human lung. Tissue sections of human lung were analyzed for expression of CFTR mRNA by in situ hybridization. These include proximal bronchioles: samples PAP (sense $[A]$ and antisense $[B]$ ) and Normal2 (antisense $[C]$ ); terminal bronchioles: samples Normal2 (sense $[D]$ and antisense $[E]$ ) and PAP (antisense $[F$ and $G]$ ); respiratory bronchioles: samples Normal2 (sense $[H]$ and antisense $[I]$ ) and PAP (antisense $[J]$ ); and alveoli: sample Normal2 (sense $[K]$ and antisense $[L]$ ) and PAP (antisense $[M]$ ). Sections hybridized with the sense probe are serial to the sections hybridized with the corresponding antisense probe. All panels show 3-wk exposures to photoemulsion with brightfield and darkfield photomicrographs on the left and right, respectively, except for $G$, which shows two higher power photomicrographs of terminal bronchioles. Arrows point to a subset of cells that intensely express CFTR within the alveolar regions of $L$ and $M$ and respiratory bronchial epithelial cells of $I$ and $J(A-F, J, K$, and $K-M:$ bar $=130 \mu \mathrm{m} ; G$ : bar $=40 \mu \mathrm{m} ; H$ and $I:$ bar $=65 \mu \mathrm{m} ; J:$ bar $=160$ $\mu \mathrm{m})$. 

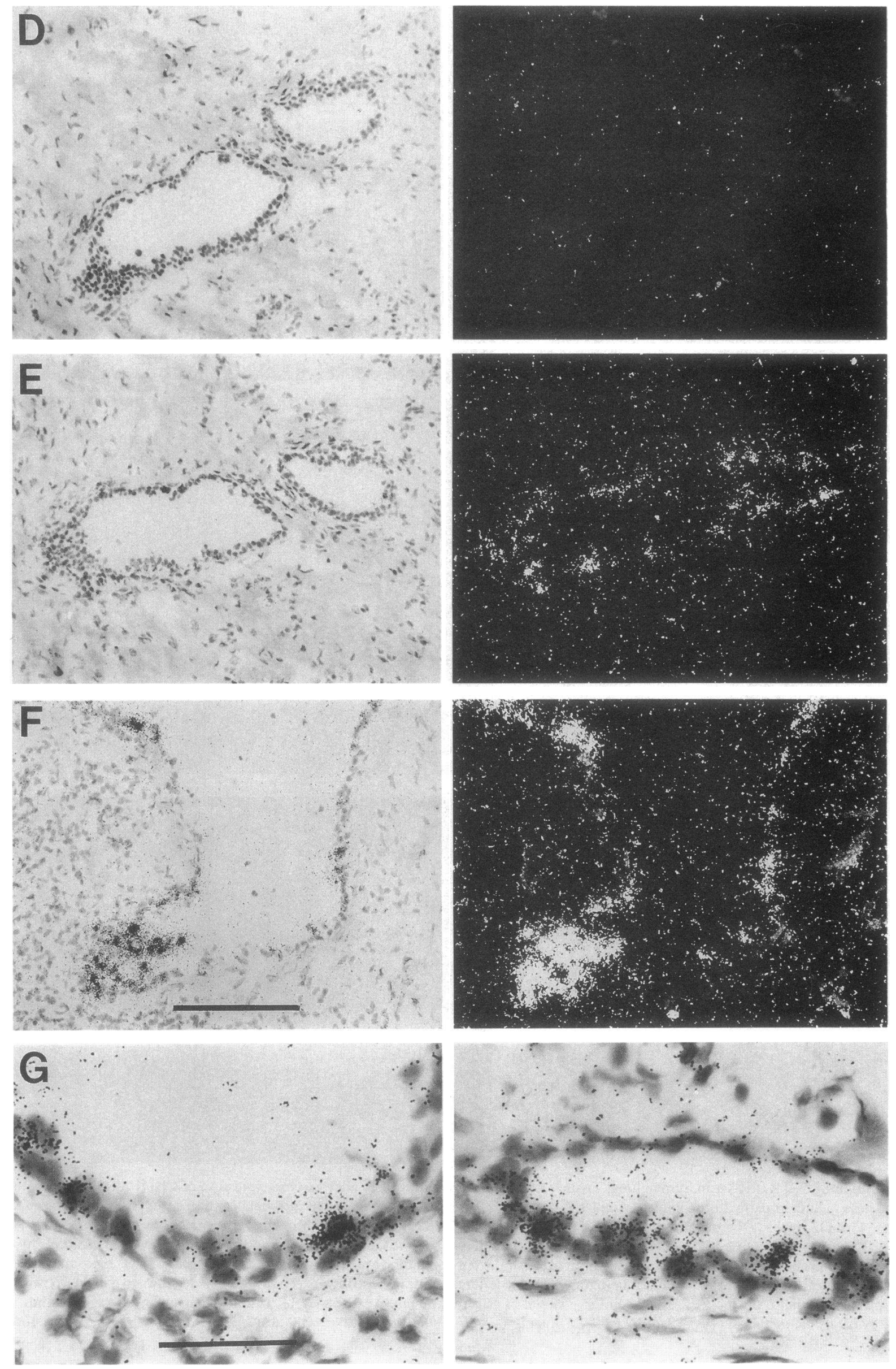

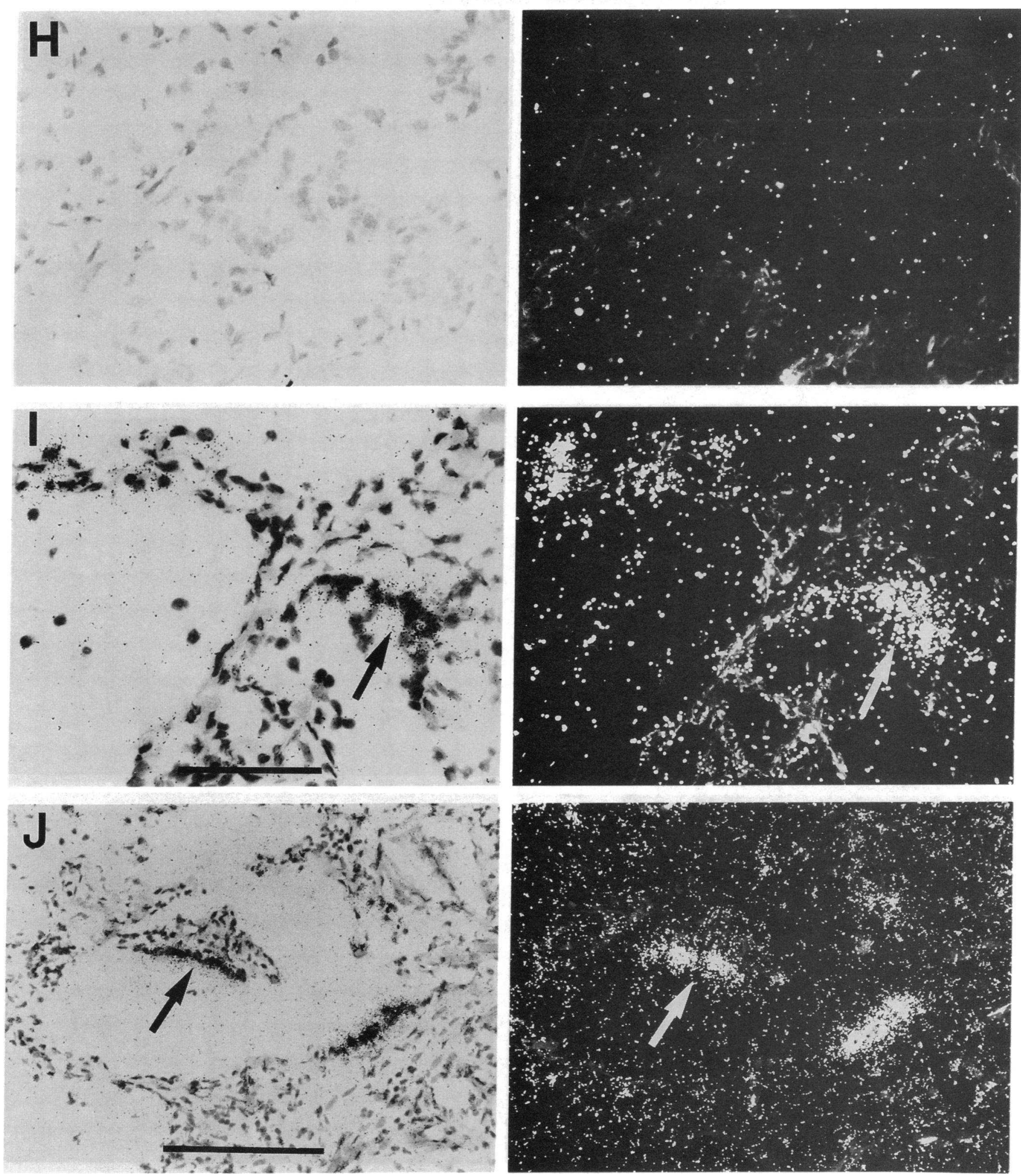

Figure 1. (Continued)

(Table II), the intensity of signal varied significantly. Because of the focal nature of the signal, it was impossible to quantify differences between samples in the intensity of highly expressing cells due to saturated signal in the highest expressing samples. Evaluation of the proximal bronchioles illustrates the type of variation in intensity and frequency that was encountered; expression ranged from very high signal in $9 \pm 5 \%$ of epithelial cells in sample PAP (Fig. $1 B$ ) to signal that was barely above background in $4 \pm 3 \%$ of epithelial in sample Normal2 (Fig. 1 $C)$. This heterogeneity may reflect the clinical status of the 

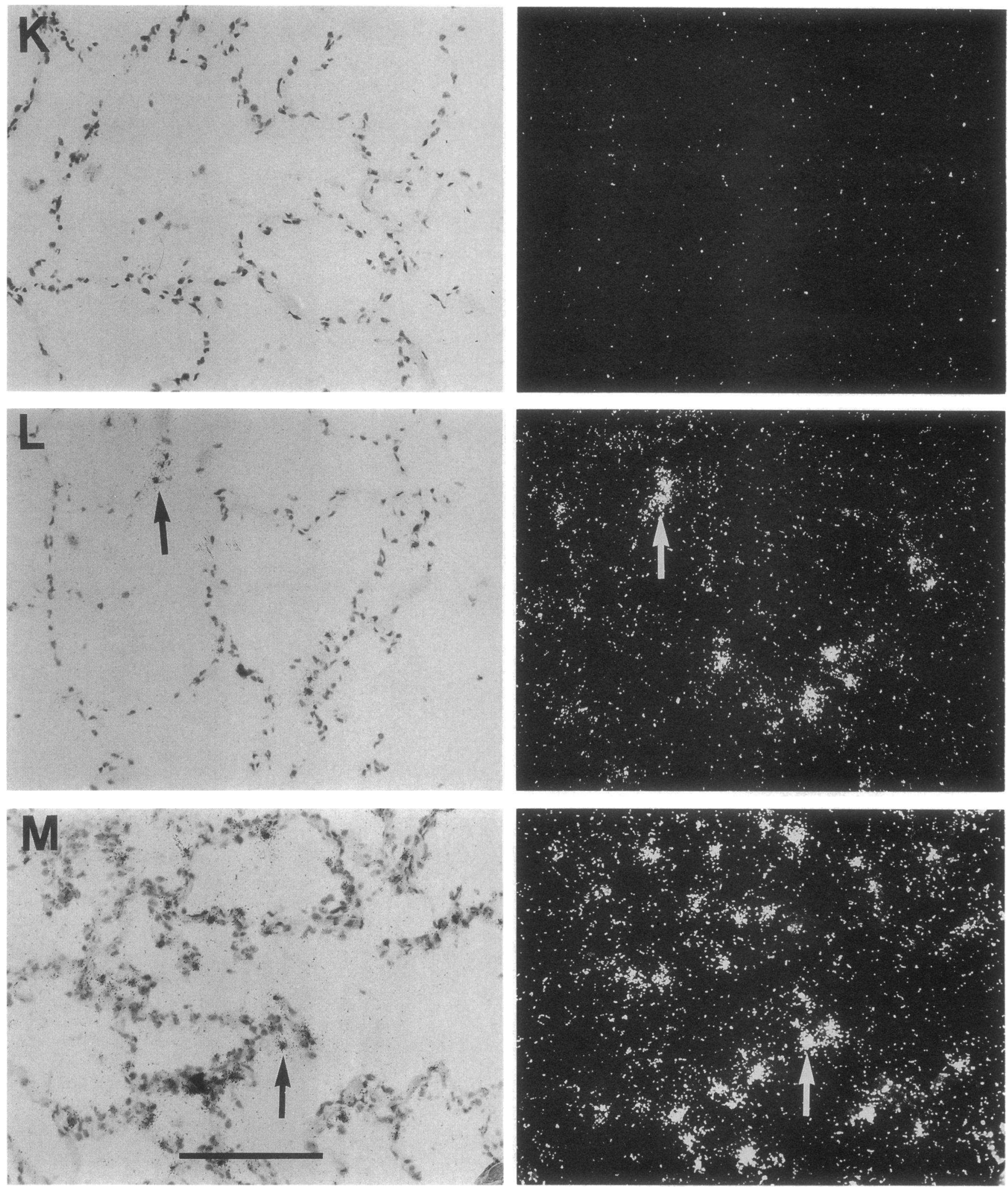

Figure 1. (Continued)

donor or heterogeneity of expression within subsegments of an individual lung.

In an attempt to quantitate the abundance of CFTR mRNA-expressing cells in a manner that was not affected by differences in airway cellular architecture, we normalized morphometric quantification to the total cell area of structures ana- lyzed. Table II summarizes the results and statistically compares the compiled data from four patients as to the abundance of CFTR-expressing cells within the various levels of the airway. In contrast to morphometric analysis normalized to total cell numbers, the number of CFTR-expressing cells normalized to cell area gave a statistically higher $(P<0.001)$ level of 
Table II. Summary of CFTR Localization: Frequency of CFTR mRNA-expressing Cells

\begin{tabular}{|c|c|c|c|c|c|}
\hline & & $\begin{array}{c}\text { Proximal } \\
\text { bronchioles }\end{array}$ & $\begin{array}{c}\text { Terminal } \\
\text { bronchioles }\end{array}$ & $\begin{array}{l}\text { Respiratory } \\
\text { bronchioles }\end{array}$ & Alveoli \\
\hline \multirow[t]{5}{*}{ Normalized to cell number* } & Normal2 & $4 \pm 3 \%$ & $4 \pm 3 \%$ & $10 \pm 10 \%$ & $1 \pm 1 \%$ \\
\hline & COPD1 & $2 \pm 3 \%$ & $3 \pm 3 \%$ & $10 \pm 4 \%$ & $2 \pm 3 \%$ \\
\hline & COPD3 & $3 \pm 2 \%$ & $3 \pm 3 \%$ & $5 \pm 5 \%$ & $3 \pm 2 \%$ \\
\hline & PAP & $9 \pm 5 \%$ & $9 \pm 4 \%$ & $7 \pm 4 \%$ & $5 \pm 2 \%$ \\
\hline & Average $^{\ddagger}$ & $5 \pm 3$ & $5 \pm 3$ & $8 \pm 3$ & $3 \pm 2$ \\
\hline \multirow[t]{5}{*}{ Normalized to cellular area } & Normal2 & $1.7 \pm 1.3$ & $1.6 \pm 0.9$ & $4.2 \pm 4.4$ & $0.2 \pm 0.2$ \\
\hline & COPDI & $0.5 \pm 0.1$ & $0.6 \pm 0.6$ & $2.7 \pm 1.3$ & $0.7 \pm 0.8$ \\
\hline & COPD3 & $1.2 \pm 0.8$ & $1.4 \pm 1.4$ & $1.5 \pm 1.5$ & $0.4 \pm 0.3$ \\
\hline & PAP & $1.2 \pm 0.4$ & $2.6 \pm 1.4$ & $2.1 \pm 1.1$ & $0.9 \pm 0.4$ \\
\hline & Average $^{\ddagger \|}$ & $1.2 \pm 0.5$ & $1.6 \pm 0.8$ & $2.6 \pm 1.2$ & $0.6 \pm 0.3$ \\
\hline
\end{tabular}

* The frequency of cells expressing > 10-fold levels of CFTR mRNA above background was counted within each of the epithelial structures and normalized to the total number of nuclei in that structure according to procedures described in Methods. Values representing averages from at least six fields are given as number of positive cells per total number of nuclei \pm 1 SD. ${ }^{\ddagger}$ The average of four patients analyzed by morphometry for each epithelial structure ( $n=24$ fields). $\$$ The frequency of cells expressing $>10$-fold levels of CFTR mRNA above background was counted within each of the epithelial structures and normalized to the total cell volume within each structure according to procedures described in Methods. Values representing the averages from at least six fields are given as number of positive cells per square micron of cellular area $\left(\times 10^{-3}\right) \pm 1$ SD. "Statistical analysis using the Student's $t$ test comparing the frequency of CFTR mRNA-positive cells in at least 24 fields of each epithelial structures, proximal bronchioles (PB), terminal bronchioles (TB), respiratory bronchioles (RP), and alveoli (A); PB vs. TB, $P<$ 0.127 ; PB vs. RB, $P<0.017$; PB vs. A, $P<0.035$; TB vs. RB, $P<0.162$; TB vs. A, $P<0.001$; and RB vs. A, $P<0.001$.

CFTR mRNA-expressing cells in the respiratory bronchioles as compared with proximal bronchioles and alveoli. No statistical difference was found between the level of CFTR expression in terminal and respiratory bronchioles $(P<0.162)$.

No conclusions as to the cell type expressing CFTR in the bronchioles could be made, as cilia were not retained after tissue preparation for in situ analysis. However, in situ grains were clustered in cells of the alveolar region that appeared cuboidal in shape, a finding most consistent with expression in type II pneumocytes rather than the squamous type I pneumocytes or intraalveolar macrophages (which were interpreted as lying within the lumen of the airspace).

CFTR protein localization. Tissue sections were analyzed for expression of CFTR protein using a polyclonal antibody directed against a COOH-terminal peptide of CFTR. The specificity and sensitivity of this antibody for immunolocalizing CFTR in tissues has been described previously (6). The specificity of CFTR immunoreactive staining in bronchioles was determined in single immunofluorescent experiments using serial sections stained with CFTR antibody preincubated with peptide antigen. Fig. 2, $A$ and $B$, shows CFTR-immunoreactive staining in a proximal and terminal bronchiole that was absent when the antibody was preincubated with peptide antigen (Fig. $2 \mathrm{C}$ ). Fluorescence signal was also absent when the primary antibody was omitted (data not shown). Tissue sections were also incubated with antibodies to CFTR and another membrane marker, the $\mathrm{Na}^{+} / \mathrm{K}^{+}$-ATPase, that localizes to the basal lateral surface of epithelial cells. Fig. 3 contains examples of CFTR expression in a proximal bronchiole $(A)$ and terminal bronchiole $(B)$. CFTR antibody bound to a subpopulation of airway epithelial cells in bronchioles of five of the six samples analyzed; the signal consistently localized to the apical surface of these cells. CFTR expression was primarily observed in nonciliated cells, as visualized under Nomarski optics (see arrows, Figs. $2 B$ and $3 A$ ). However, in sections where morphologic retention of the ciliated layer was inadequate, as indicated by compressed cilia, it was impossible to exclude the possibility that high levels of CFTR were also expressed in a subset of ciliated cells. CFTR protein localization in respiratory bronchioles and alveolar regions was difficult due to high levels of autofluorescence (which appears as a yellowish-orange fluorescence on the FITC channel), as indicated by fluorescent signal in FITC, Texas red, and UV channels of sections not treated with secondary antibody. Nonspecific binding of primary antibody to endothelial cells of alveolar capillaries also made protein localization difficult in this region. Hence, no conclusions at present can be made about the cell type that expressed CFTR protein in respiratory bronchioles and alveoli.

CC10 mRNA localization. In an attempt to further characterize the cell type that expresses CFTR, three tissues samples that showed high-level CFTR hybridization were also analyzed for expression of the cell-specific marker $\mathrm{CC10}$ by in situ hybridization. This gene encodes a $10-\mathrm{kD}$ secreted protein that is believed to be specific to a subtype of Clara cells $(10,12)$. Very high levels of hybridization to the antisense $\mathrm{CC} 10$ probe were demonstrated in $>50 \%$ of the cells of the proximal bronchioles (Fig. $4 \mathrm{~B}$ ) of all three patients analyzed. Serial sections hybridized with the sense probe (Fig. $4 A$ ) or pretreated with RNAse before hybridization to the antisense probe (data not shown) failed to demonstrate signal over background. Expression of $\mathrm{CC} 10$ was substantially lower in the terminal and respiratory bronchioles of one sample (PAP; Fig. $4 B$ ) and was absent from these regions in the two other samples (Normal2 and COPD3; data not shown ). Signal was absent in the alveolar regions from all samples analyzed.

To more closely analyze the potential overlap of $\mathrm{CC} 10$ and CFTR mRNA expression, serial sections from the three samples described above were hybridized to either the $\mathrm{CC} 10$ or CFTR antisense mRNA probes. Fig. 5 illustrates the findings 

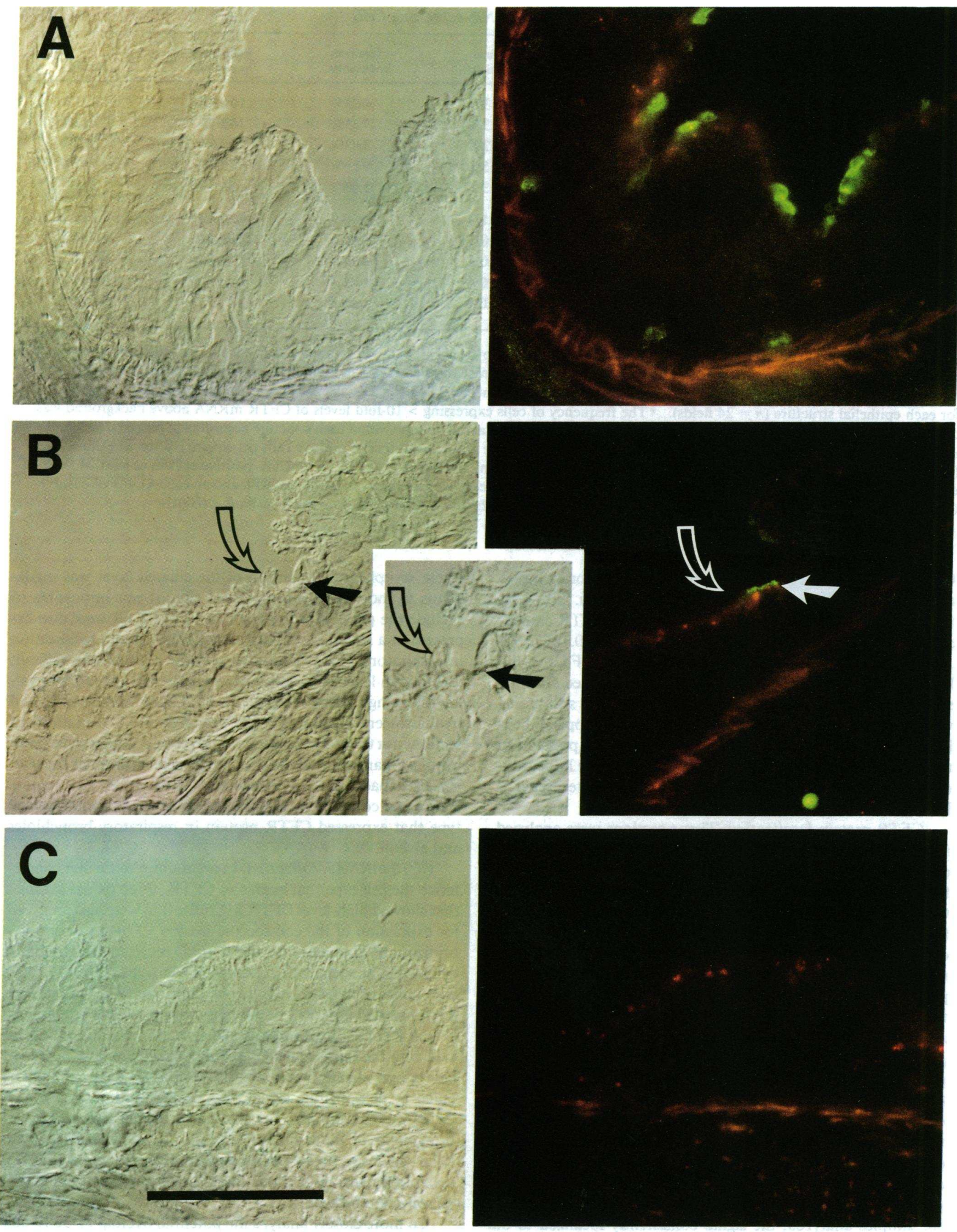

Figure 2. Peptide competition of CFTR protein localization in bronchioles. Immunocytochemical localization of CFTR protein expression in lung sections was analyzed by peptide competition in serial section. $(A)$ Pattern of CFTR expression detected with FITC within a proximal bronchiole in the absence of peptide antigen. Shown are localization of CFTR within serial sections of a terminal bronchioles in the absence of peptide antigen $(B)$ and after preincubation of the $\alpha 1468$ antibody with peptide antigen $(C)$. The open arrows mark a ciliated cell, while the filled arrows mark a CFTR-expressing nonciliated cell. Each set consists of a Nomarski (left) and immunofluorescent (right) photomicrograph $(\mathrm{bar}=53 \mu \mathrm{m})$. 


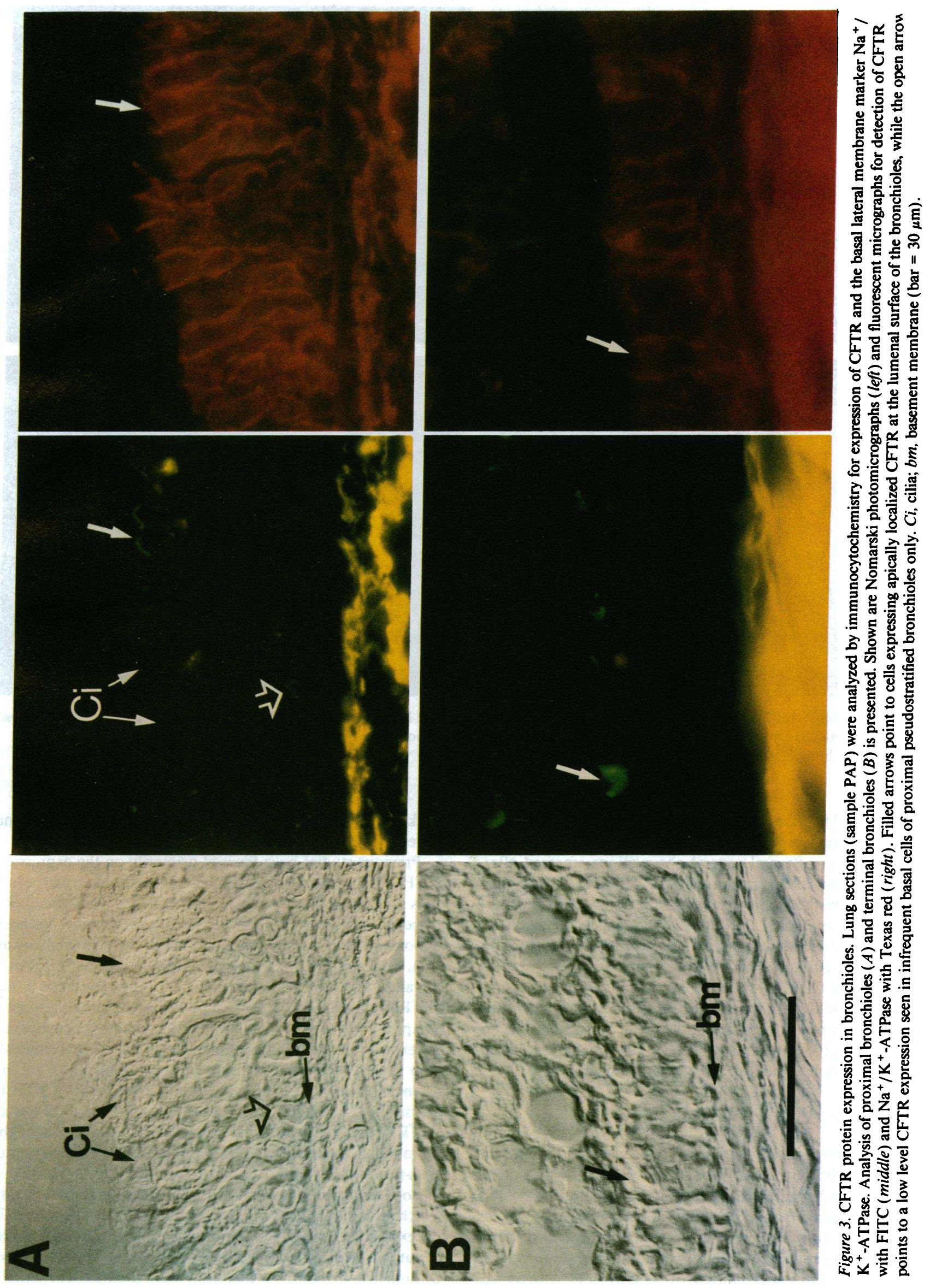



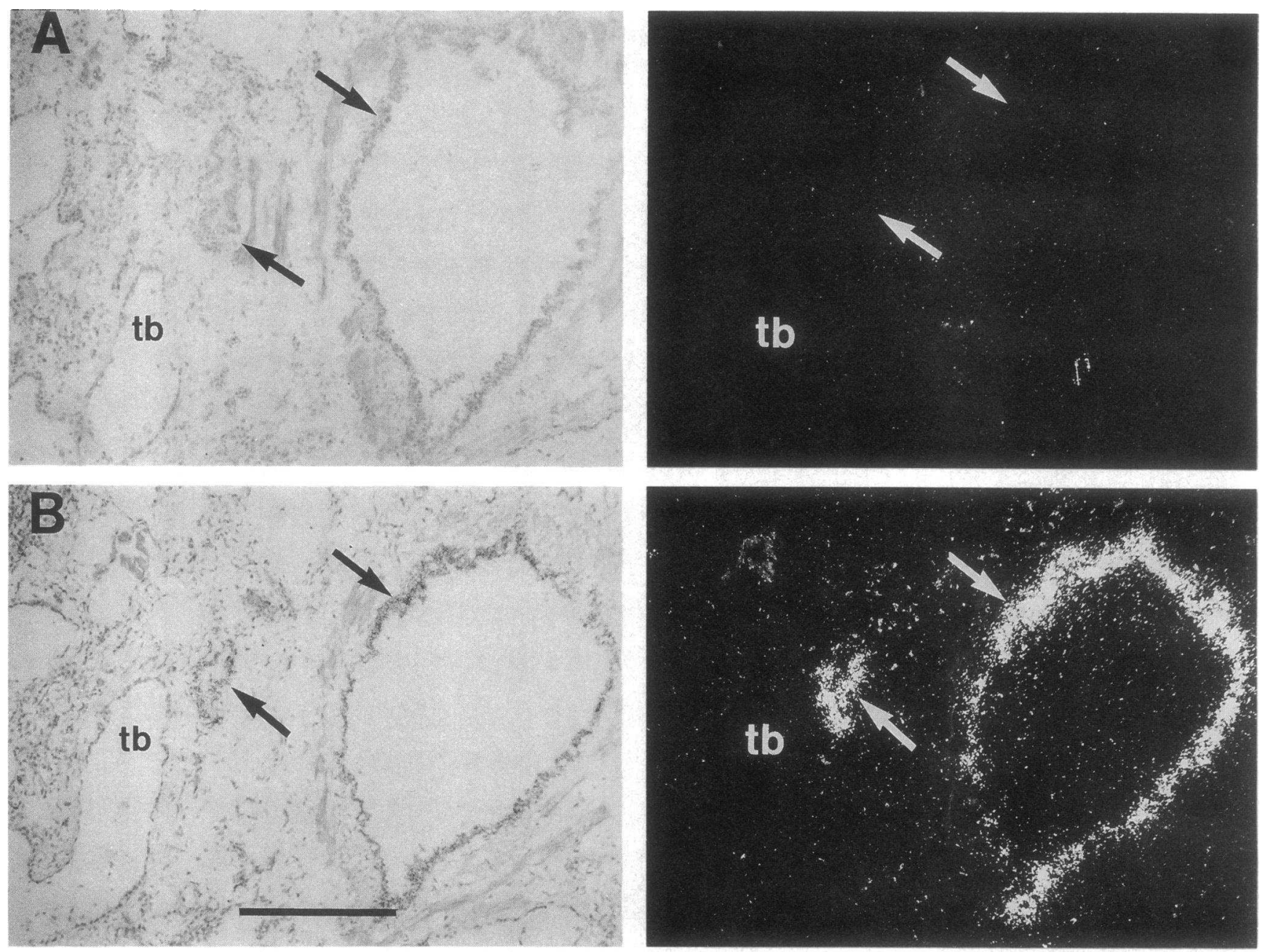

Figure 4. Localization of CC10 mRNA. Sections from tissue sample PAP were hybridized to CC10 sense $(A)$ and antisense $(B)$ RNA probes. Shown are brightfield (left ) and darkfield ( right) photomicrographs. Photoemulsion was exposed for $18 \mathrm{~h} . t b$, terminal bronchiole; arrows mark pseudostratified bronchioles (bar $=260 \mu \mathrm{m})$.

with sample PAP, with representative examples of $\mathrm{CC} 10$ and CFTR expression in proximal bronchioles $(A$ and $B)$ and alveoli $(C$ and $D)$. Several general observations emerged after review of this sample. When present, the level of CC10 expression was dramatically higher than the level of CFTR expression. In all bronchioles, CFTR was expressed in the same regions as $\mathrm{CC10}$. However, alveolar cells expressed CFTR in the absence of $\mathrm{CC} 10$ expression. Analysis of the other two samples (Normal2 and COPD3) revealed overlap of CFTR expression in a subset of $\mathrm{CC} 10$-expressing cells of the proximal bronchioles and a normal distribution of CFTR expression with an absence of $\mathrm{CC} 10$ expression in the terminal bronchioles, respiratory bronchioles, and alveoli (data not shown).

\section{Discussion}

Despite tremendous insight into the genetic and molecular basis of CF, little is known about the basic pathophysiology that underlies the pulmonary manifestations of the disease. It is generally believed that an important primary abnormality lies in the conducting airways where defective mucociliary clearance leads to obstructive lung disease and chronic infections (1). Critical to an understanding of these pathologic processes is a knowledge of the distribution and regulation of CF gene expression in adult human lung.

Previous studies have focused primarily on the expression of CFTR in surface epithelial cells of proximal airway structures such as the nose, trachea, and bronchus. Functional evidence for the existence of the CFTR chloride channel has been demonstrated in surface epithelial cells of the proximal airway (13), however, attempts to detect and localize the CFTR protein and RNA have been difficult (3-5). One hypothesis is that CFTR plays a role in the normal physiology of these cells but it is expressed at very low levels (6). We recently characterized the expression of CFTR in human bronchus using techniques of in situ hybridization and immunocytochemistry (6). Consistent with previous studies, we found low levels of CFTR in the surface epithelium. However, substantial expression of CFTR expression was found in serous cells and ducts of the submucosal glands. This directly implicates an important mucous-producing structure of the proximal lung in the pathogenesis of CF lung disease. It is unlikely that submucosal glands, which are restricted to cartilaginous airway, play a direct role in the extensive obstructive lung disease found in the distal airway of patients with CF. In this report, techniques of in situ hybridization and immunocytochemistry were used to delineate the 

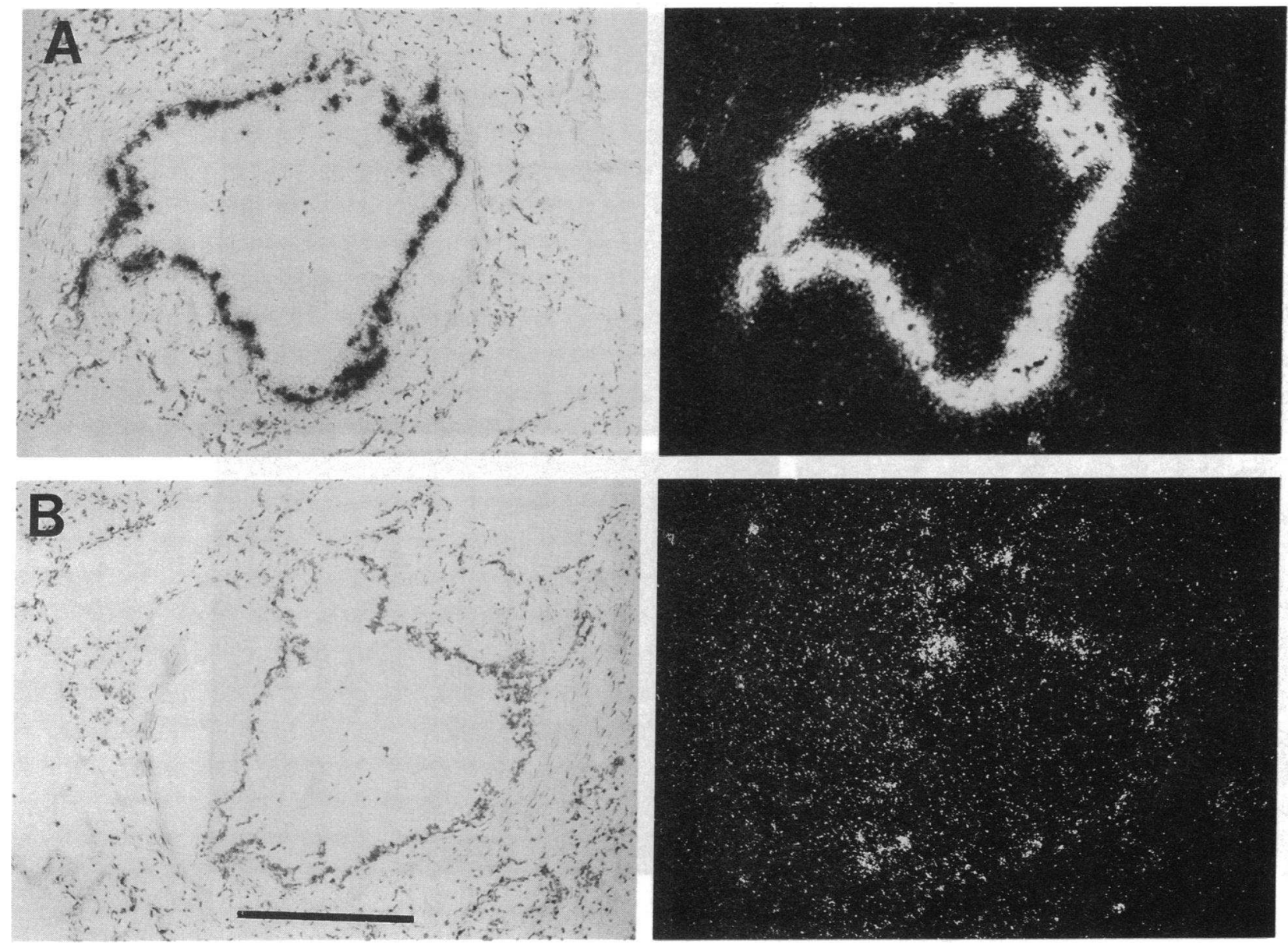

Figure 5. Localization of CFTR and CC10 mRNA in serial sections. Serial sections from sample PAP were hybridized to CC10 $(A$ and $C)$ and CFTR $(B$ and $D$ ) antisense probes and developed for $18 \mathrm{~h}$ and $2 \mathrm{wk}$, respectively. Shown are brightfield (left) and darkfield (right) photomicrographs. No signal was seen with either CC10 or CFTR sense probes or with RNAse-pretreated slides hybridized with antisense probe, data not shown $(A$ and $B:$ bar $=260 \mu \mathrm{m} ; C$ and $D:$ bar $=200 \mu \mathrm{m})$.

distribution of CFTR expression in distal airways and alveolar regions of adult human lung.

This study demonstrates detectable levels of CFTR RNA and protein in a subpopulation of epithelial cells in every structure distal to the bronchus, including proximal, terminal, and respiratory bronchioles, and alveoli. Although the pattern of expression within the lung was fairly consistent between patients, in that $1-10 \%$ highly expressing cells could be found throughout all levels of the distal lung, the intensity of signal varied substantially from patient to patient. This sample-specific variation in CFTR expression remains unexplained, but could be related to environmental influences and/or heterogeneity of expression within subsegments of an individual lung.

The general pattern of CFTR expression in the distal lung. that emerged from our studies has implications in several areas of CF biology. Morphometric analysis of CFTR-expressing cells normalized to cellular area in the various airway structures shows a statistically significant trend that revealed highest levels in respiratory bronchioles as compared with proximal bronchioles (twofold, $P<0.001$ ) and alveoli (fivefold, $P$ $<0.001$ ). Comparison of terminal and respiratory bronchioles showed no statistical differences in the abundance of CFTR mRNA-expressing cells, suggesting that these structures may be functionally related in their capacity to facilitate CFTR-me- diated chloride transport. An additional recurrent finding was that CFTR did not appear to be expressed uniformly throughout the lung, in that a minority of highly expressing cells (1$10 \%$ of total cells) can be seen in bronchioles and alveoli. This is reminiscent of the pattern of CFTR expression in the submucosal gland ducts of human bronchus where $1-2 \%$ of the duct cells expressed high levels ( $>50$ fold over background) of CFTR mRNA and protein (6). This pattern of expression is consistent with regulation of chloride transport through a minority subpopulation of cells in a heterogeneous epithelium. Models of this type of chloride transport regulation have been extensively studies in systems such as the amphibian skin where mitochondria rich flask cells, which constitute $1-2 \%$ of the entire dermal layer, are the sole route of chloride uptake $(14,15)$.

In the bronchioles it is clear that ciliated cells do not express detectable levels of CFTR protein, suggesting that other cells in these epithelia may be involved in CFTR expression. The distribution and biology of nonciliated cells of human distal airway are not well described. Extrapolation from studies in nonhuman primates (16) suggests that the distal airways contain a variety of cell types, including ciliated cells, mucous cells, basal cells, and nonciliated secretory cells containing electron-dense granules (also known as Clara cells [17]). Our analysis of prox- 

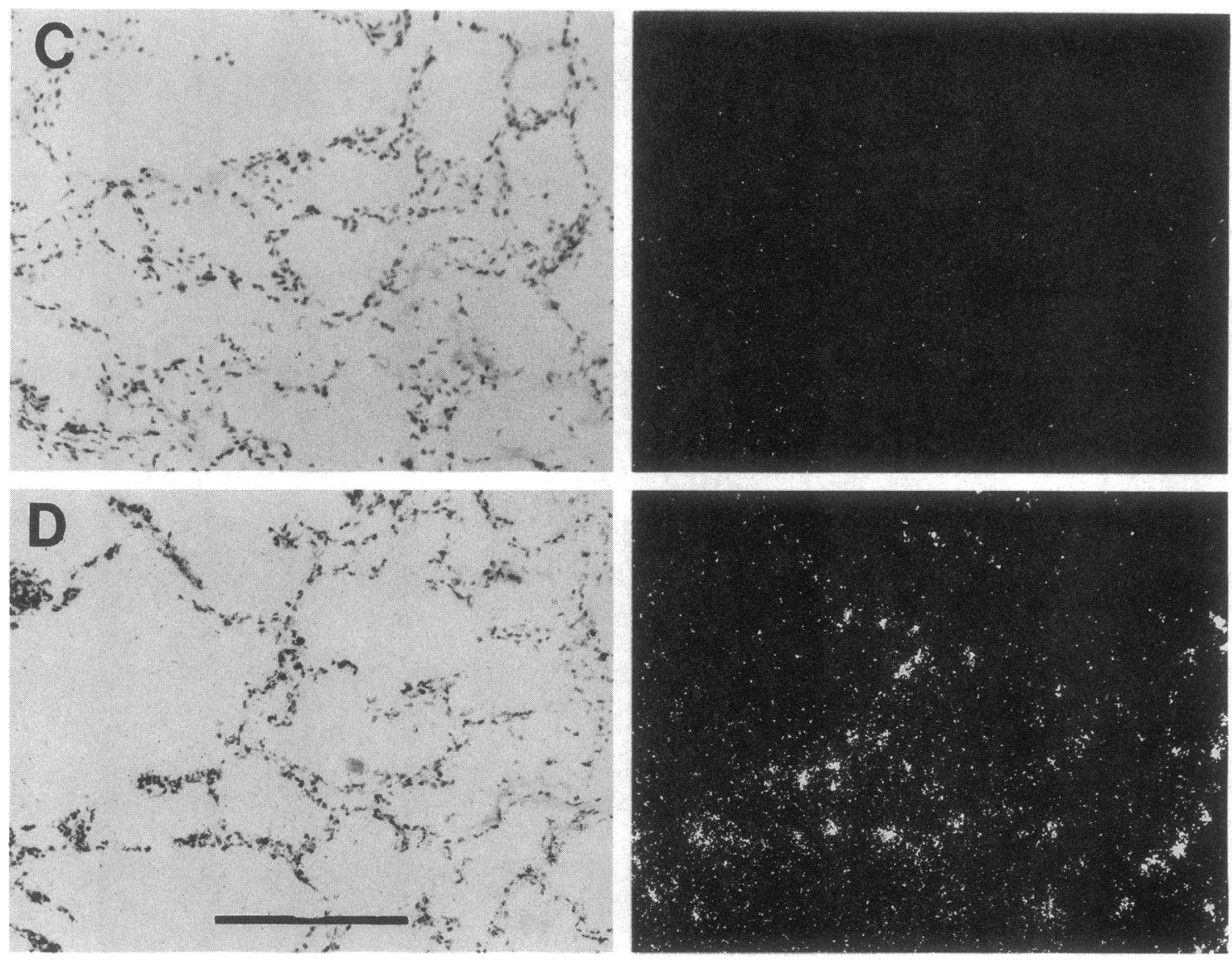

Figure 5. (Continued)

imal bronchioles demonstrated extensive expression of the Clara cell marker $\mathrm{CC10}$ within regions that also express CFTR (see Fig. 6 for summary). The resolution of this analysis was insufficient to study colocalization at a cellular level. However, the lack of complete concordance between CFTR and CC10 in
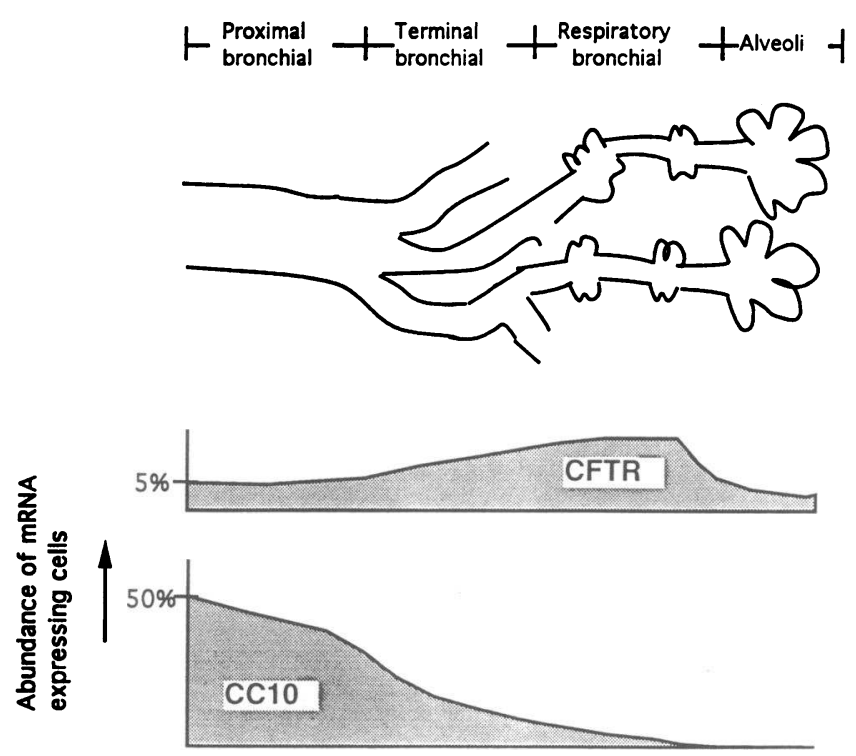

Figure 6. Schematic representation of CFTR and CC10 mRNA expression at various levels of airway in human lung. proximal bronchioles is consistent with CFTR expression primarily in either a subpopulation of Clara cells or in another nonciliated cell type. The previous demonstration of CAMPmediated $\mathrm{Cl}^{-}$transport in rabbit Clara cells (18) is consistent with the presence of CFTR in this cell type. Analysis in terminal bronchioles, respiratory bronchioles, and alveoli revealed substantial expression of CFTR in a large number of nonCC10-expressing cells; the identity of these nonciliated CFTRexpressing cells in unknown. Our studies provide direct support for the role of CFTR in distal airway disease of the human adult CF lung. Furthermore, these studies suggest that alveolar cells may be involved in primary pathogenesis.

The heterogeneous pattern of CFTR expression in distal regions of the lung has implications on our understanding of the basic biology of chloride transport in this tissue and may help elucidate a better understanding of the pathophysiology of lung diseases such as CF. These findings will likely affect the approaches for gene therapy strategies for CF in that it will be important to determine whether the CFTR gene must be directed to specific cell types throughout the lung to prove effective.

\section{Acknowledgments}

We thank Sonia Janich and Lorita Dudus for technical support and Dr. Gurmukh Singh for the human CC10 cDNA.

This work was supported by the Cystic Fibrosis Foundation and National Institutes of Health grant HL-34322. 


\section{References}

1. Boat, T. F., M. J. Welsh, and A. L. Beaudet. 1989. Cystic fibrosis. In The Metabolic Basis of Inherited Disease. 6th ed. C. R. Scriver, A. L. Beaudet, W. S. Sly, and D. Valle, editors. McGraw-Hill Inc., New York. 2649-2680.

2. Collins, F. S. 1992. Cystic fibrosis: molecular biology and therapeutic implications. Science (Wash. DC). 256:774-779.

3. Trapnell, B. C., C. S. Chu, P. K. Paakko, T. C. Banks, K. Yoshimura, V. J. Ferrans, M. S. Chernick, and R. G. Crystal. 1991. Expression of the cystic fibrosis transmembrane conductance regulator gene in the respiratory tract of normal individuals and individuals with cystic fibrosis. Proc. Natl. Acad. Sci. USA. 88:6565-6569.

4. Zeitlin, P. L., I. Crawford, L. Lu, S. Woel, M. E. Cohen, M. Donowitz, M. H. Montrose, A. Hamosh, G. R. Cutting, D. Gruenert, et al. 1992. CFTR protein expression in primary and cultured epithelia. Proc. Natl. Acad. Sci. USA. 89:344-347.

5. Sarkadi, B., D. Bauzon, W. R. Huckle, H. S. Earp, A. Berry, H. Suchindran, E. M. Price, J. C. Olson, R. C. Boucher, and G. A. Scarborough. 1992. Biochemical characterization of the cystic fibrosis transmembrane conductance regulator in normal and cystic fibrosis epithelial cells. J. Biol. Chem. 267:2087-2095.

6. Engelhardt, J. F., J. R. Yankaskas, S. A. Ernst, Y. Yang, C. R. Marino, R. C. Boucher, J. A. Cohn, and J. M. Wilson. 1992. Submucosal glands are the predominant site of CFTR expression in the human bronchus. Nature Genetics. 2:240248.

7. McCray, P. B., Jr., C. L. Wohlford-Lenane, and J. M. Snyder. 1992. Localization of cystic fibrosis transmembrane conductance regulator $\mathrm{mRNA}$ in human fetal lung tissue by in situ hybridization. J. Clin. Invest. 90:619-625.

8. Breeze, R. G., and E. B. Wheeldon. 1977. The cells of the pulmonary airways. Am. Rev. Respir. Dis. 116:705-777.
9. Riordan, J. R., J. M. Rommens, B. Kerem, N. Alon, R. Rozmahel, Z. Grzelczak, J. Zielenski, S. Lok, N. Plavsic, J. L. Chou, et al. 1989. Identification of the cystic fibrosis gene: cloning and characterization of complementary DNA. Science (Wash. DC). 245:1066-1073.

10. Singh, G., S. L. Katyal, W. E. Brown, S. Phillips, A. L. Kennedy, J. Anthony, and N. Squeglia. 1988. Amino-acid and CDNA nucleotide sequences of human Clara cell $10 \mathrm{kDa}$ protein. Biochim. Biophys. Acta. 950:329-337.

11. Pietrini, G., M. Matteoli, G. Banker, and M. J. Caplan. 1992. Isoforms of the Na,K-ATPase are present in both axons and dendrites of hippocampal neurons in culture. Proc. Natl. Acad. Sci. USA. 89:8414-8418.

12. Manabe, T., H. Ikeda, T. Moriya, and K. Yamashita. 1987. Immunohistochemical localization of the secretory products of rat Clara cells. Anat Rec 217:164-171

13. Quinton, P. M. 1990. Cystic fibrosis: a disease in electrolyte transport FASEB (Fed. Am. Soc. Exp. Biol.) J. 4:2709-2717.

14. Larsen, E. H. 1991. Chloride transport by high-resistance heterocellular epithelia. Physiol. Rev. 71:235-283.

15. Katz, U., and C. Scheffey. 1986. The voltage-dependent chloride current conductance of toad skin is localized to mitochondria-rich cells. Biochim. Biophys. Acta. 861:480-482.

16. Tyler, N. K., and C. G. Plopper. 1985. Morphology of the distal conducting airways in rhesus monkey lungs. Anat. Rec. 211:295-303.

17. Plopper, C. G., D. M. Hyde, and A. R. Buckpitt. 1991. Clara cells. In The Lung: Scientific Foundations. Vol. 1. R. G. Crystal, J. B. West, P. J. Barnes, N. S Cherniack, and E. R. Weibel, editors. Raven Press, Ltd., New York. 215-228.

18. Van Scott, M. R., C. W. Davis, and R. C. Boucher. 1989. $\mathrm{Na}^{+}$and $\mathrm{Cl}^{-}$ transport across rabbit nonciliated bronchiolar epithelial (Clara) cells. Am. J. Phvsiol. 256:C893-901. 